\title{
Technology Use by Urban Local Bodies in India to Combat the COVID-19 Pandemic
}

\author{
Falguni Mukherjee, Sam Houston State University, USA \\ (iD) https://orcid.org/0000-0001-9073-2608
}

\begin{abstract}
This article provides a comprehensive review of the use of information and communication technologies by urban local bodies in India in their war against the COVID-19 pandemic based on a detailed survey conducted during the pandemic period. India reported its first case of COVID-19 in late January, and government authorities have been on a war footing since then to curb the spread of the virus. Following a tradition that has been instilled within government agencies since the Modi Government came into power in 2014, local, state, and central government agencies turned to a widespread use of geospatial, surveillance and information and communication technologies as part of a strategy to monitor and track movement, manage individuals, and enforce quarantine norms. However, several important questions arise from the blind use of technology that remain unanswered. The use of technology by government agencies raise key questions on privacy, civil liberties, and suitability and viability of their use.
\end{abstract}

\section{KEYWORDS}

COVID-19, Geospatial Technology, India, Surveillance, Tracking Apps

\section{INTRODUCTION}

In December 2019 the novel coronavirus, COVID-19 originated in Wuhan, Hubei province, China. The virus spread rapidly to other parts of the country and globally to other countries around the world. The infections spread very quickly and the SARS-CoV-2 coronavirus infected 1000 individuals in a matter of 48 days, equivalent to the number of infections by Middle East Respiratory Syndrome - related coronavirus (MERS) in two and a half years from 2012 to 2014 and by SARS infection in 2002-2003 in a period of two months (Boulos and Geraghty, 2020). On January 30, 2020 the World Health Organization (WHO) declared the new SARS-CoV-2 coronavirus outbreak a Public Health Emergency of International Concern (PHEIC) (WHO, 2020).

The disease caused by the SARS-CoV-2 coronavirus is characterized by mild to severe acute upper respiratory symptoms. Older adults and individuals with underlying medical conditions are more susceptible to developing serious complications from the disease (CDC, 2020). Currently, there are 11.6 million confirmed cases of COVID-19 and 538,828 deaths worldwide (John Hopkins Coronavirus Resource Center, accessed on 7/7/2020). The disease has presented the world with unique social and economic challenges bringing the world's healthcare system to its knees. In the absence 
of an appropriate pharmacological intervention the most prevalent non-pharmaceutical measures implemented worldwide include shelter in place, social-distancing and lockdowns. Such measures have been implemented with varying degrees of severity in different parts of the world including India. For instance, in late March 2020 the Modi government in India announced a complete lockdown to prevent the spread of the virus that has infected 719,664 individuals so far (data retrieved on July 7, 2020).

Following the announcement, the country's 1.3 billion population was mandated to self-isolate that continued for 40 days. All international flights to India were discontinued and the government put forth very stringent quarantine and containment measures to establish strict social distancing measures which included "janta curfew" and non-attendance of work and school among others. Social distancing and surveillance and monitoring of individuals to track movement are the two measures that have seen widespread administration throughout India. State and local government bodies have turned to technologies that are utilized for urban governance purposes to manage and monitor quarantining norms, track individuals and public health service deliveries and curb the spread of the virus.

Social distancing is one of the prevalent and an important non-pharmaceutical measure recommended by the Centre for Disease Control (CDC) to minimize the spread of COVID-19 that recommends individuals maintain a physical distance of 6 feet from other people (CDC, 2020). The CDC and World Health Organization (WHO) recommend practicing physical distancing in conjunction with other preventive measures, an approach adopted by many countries including India with great fervor. A key criteria to maintain these norms mandates one to have access to resources that include space, basic services and a robust social safety net. However, for many countries in the Global South where people struggle to access basic necessities it is practically impossible to gain access to these resources. The situation is particularly grim in countries like India plagued by urban and rural poverty. There is no doubt that India has taken huge strides in reducing poverty and the country's economy has grown exponentially in the past decade (Roser and Ortiz-Ospina, 2019). However, this has done little to improve conditions for many. Approximately 200 million people in the county dwell in overcrowded slums and survive on a day-to-day basis with unreliable access to basic services like drinking water and sanitation (Du et al., 2020). Conditions are especially bleak for the urban poor that mainly comprises of informal workers. Such individuals are invisible to the formal structures of society and suffer from food insecurity, income or job insecurity and housing insecurity. And members of this "informal invisible" section of the society are impacted the most by the pandemic. So how does the government provide, manage, monitor or curb the spread of infection for this particularly vulnerable population group?

Another key measure adopted by the Indian government to monitor infected and quarantined individuals involves the use of different information, communication and surveillance technologies (ICSTs). The Indian government under the leadership of Prime Minister Mr. Narendra Modi has introduced several reforms in the past two decades that promote the use of ICTs, especially targeting urban governance (Mukherjee, forthcoming). One of the key initiatives of the Prime Minister's Office since 2014 has been informationization of central, regional and local government organizations to build a Digital India (Mukherjee, forthcoming). And in face of the pandemic local government bodies (ULBs) have turned to these technologies that form an integral part of managing and monitoring the movement of infected and quarantined individuals (Datta, 2020).

In this article, I provide a thorough review of different technological measures normally utilized for urban governance that have been implemented by the Indian government at the local levels to manage the situation in the wake of the SARS-CoV-2 (COVID-19) pandemic based on a comprehensive review of technological measures employed by different government agencies in India.

\section{USE OF TECHNOLOGIES}

Government authorities in India have waged a "war" against the SARS-CoV-2 coronavirus and ULBs and State departments are using CCTVs, drones, surveillance technologies and contact tracing 
applications as part of the strategy. Government agencies at the local, regional and central levels have taken different technological initiatives in this direction and at the forefront of technological use are the cities that are part of the Smart Cities Programme. The most common technological tool that has been employed is the collection of location data from smartphones and mobile phone networks and cellular towers for surveillance purposes.

In their war against COVID-19, ULBs in cities like Surat, Pune, Begaluru and Tumakuru have converted their integrated command and control centers into COVID-19 war rooms (Smart Cities Council). These war rooms are being utilized to gather and provide up to date information on COVID-19 to city administration. The war rooms have implemented different initiatives that include surveillance of general public using CCTV cameras, tracking healthcare workers using GPS devices, mapping COVID-19 positive cases and containment zones within the city using GIS technology and tracking ambulances and disinfection services in real-time. In cities that are part of the Indian Smart Cities Programme their Smart Cities Development office are collaborating with the ULB.

For instance, the Pune Smart City Development Corporation Limited is working in conjunction with the Pune Municipal Corporation (PMC) and has developed a dashboard that is used for monitoring, tracking and surveillance purposes. The ULB has made use of GIS technology to map virus hotspots and create containment zones. The dashboard is used to monitor operations at the city's infectious disease hospital, quarantine facilities and track patients who have tested positive. This information is used by the city administration to take appropriate measures including placing contacts of patients under home quarantine.

Similarly, Surat Municipal Corporation (SMC) that is also part of Smart Cities Programme has published a dashboard on the ULB's website to provide regular updates related to COVID-19. The ULB has a history of using GIS for urban governance practices and during the pandemic has made use of geospatial technology to map and analyze public health data. The ULB has spatially mapped COVID-19 hotspots available to the public via its website. SMC has built a Surat Smart City Center (SMAC) that functions as an Integrated Command and Control Centre (ICCC) for managing city operations. A key feature of the SMAC center is a video wall covering an area of 240 square feet. One of the key elements showcased on this wall is a dashboard that provides detailed information in conjunction with the SMC's web GIS application to ULB officials. In the wake of the pandemic SMC's SMAC center has been converted into a COVID "war room" and the dashboard is being made available on the ULB website to provide COVID related information. Moreover, SMC has also introduced a smartphone app called SMC COVID - 19 Tracker. All individuals who are home quarantined must install the app on their phone and use it record their location and travel history. Quarantined individuals must also take a selfie every hour and send it to civic authorities using the app. The app is geotagged allowing SMC to track the movement of quarantined individuals. If a quarantined individual moves more than 10 meters from their home the app immediately alerts civic authorities thus allowing officials to constantly monitor quarantined individuals.

In yet another instance in Begaluru in the south Indian state of Karnataka, that is also part of Smart Cities Programme, the ULB Bruhat Bengaluru Mahanagara Palike (BBMP) has converted their command control center into a "war room" (Figure 1) to combat COVID-19.

Like many other ULBs, BBMP is using technology for surveillance, tracking and monitoring purposes. Similar to SMC, BBMP is also using a COVID-19 dashboard available in the "war room". The dashboard integrates a GIS platform with other data analytics and predictive applications. This dashboard is used to conduct surveillance of infected patients in order to curb the spread of the virus. The dashboard is also used to gather COVID-19 related data. This data is analyzed for trends and categorized into different groups and published for the general public on a daily basis. A screenshot of the dashboard is shown in Figure 2.

BBMP has also introduced a smartphone app, Quarantine Watch Mobile App with geotagging feature. All quarantined individuals are mandated to use this app by Karnataka Health Department. As per the order those under home quarantine must upload a selfie on an hourly basis using the Quarantine 
Figure 1. BBMP COVID war room

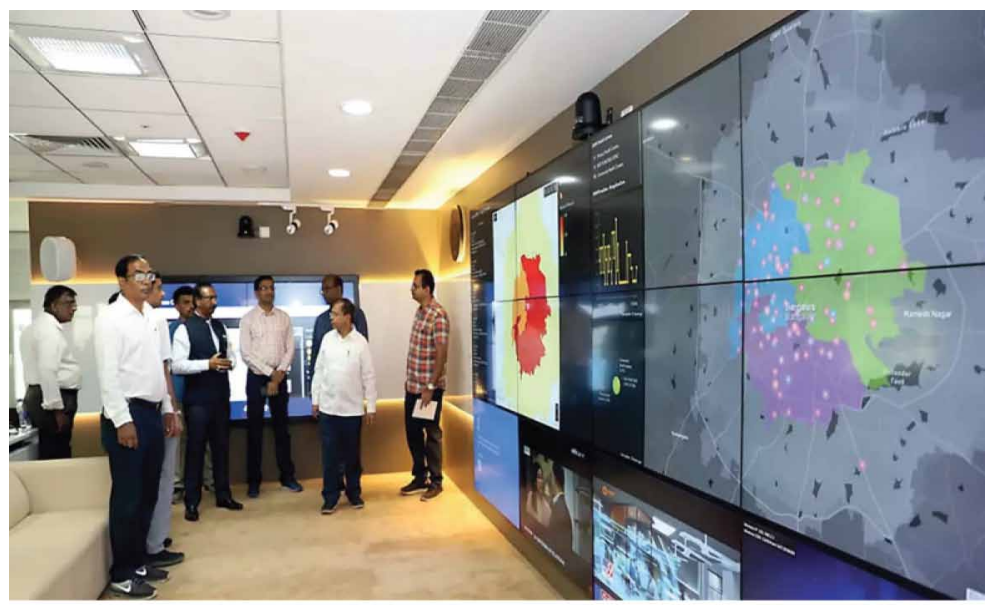

(Photo credit: Bangalore Mirror)

Figure 2. Dashboard used at BBMP COVID war room

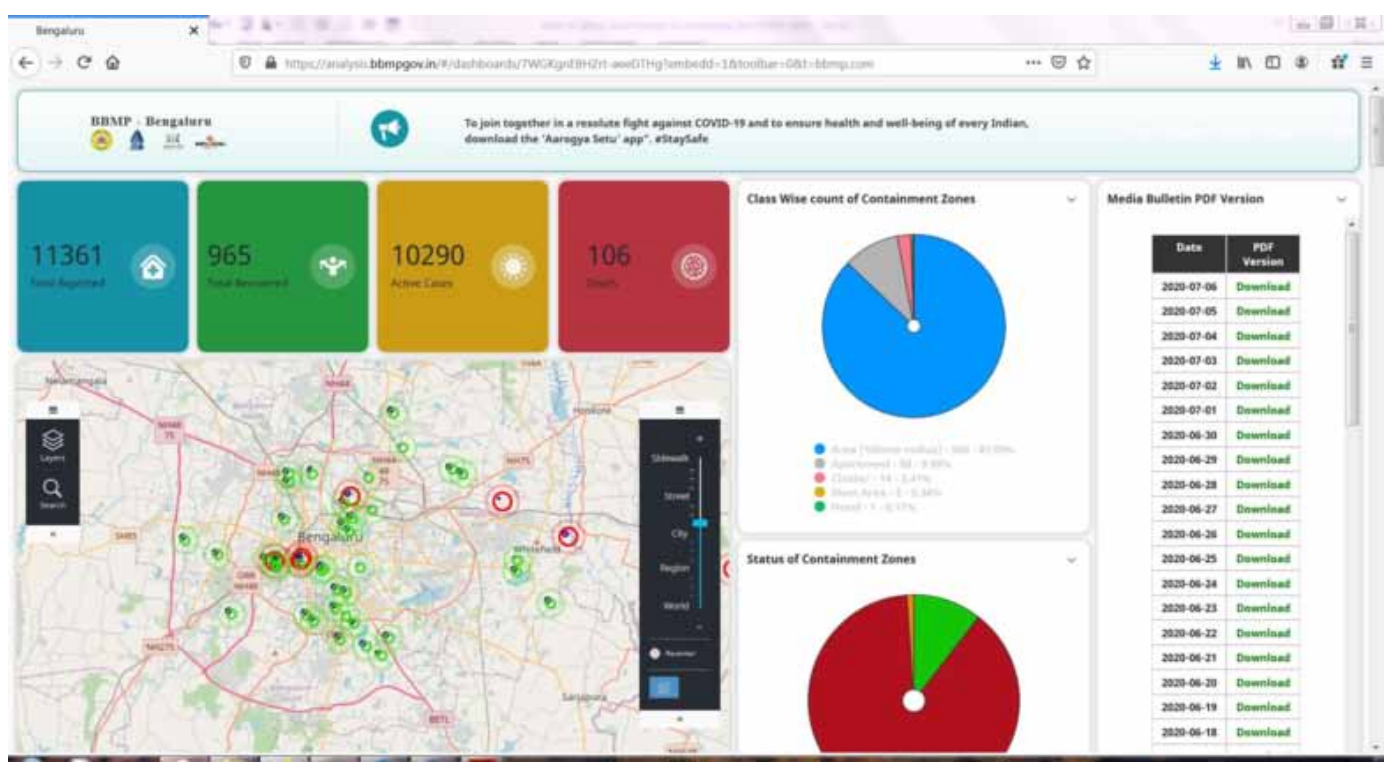

Watch Mobile app. Since the selfie would be geotagged officials will be able to verify the authenticity of the selfie as well ascertain maintenance of quarantine by individuals. BBMP has also introduced a mobile application for individuals residing within containment zones ${ }^{1}$ that have been sealed due to positive cases of COVID-19. The app named, 'BBMP Contains' aims to be a grievance redressal platform as well as a surveillance platform for civic authorities to monitor and maintain quarantine rules. Individuals with access to the app can upload photographs and videos of anyone violating lockdown to register a complaint. These complaints will be viewed by civic authorities in the BBMP "war room" to take appropriate action. The BBMP Contains app can also be used for health related emergency and for requesting essential services. BBMP has also introduced an artificial intelligence based app that can be used by COVID-19 patients to find hospital beds. The State of Karnataka 
has introduced other smartphones apps as well such as the Quarantine Watch app to track travelers travelling into the state and to enforce quarantine norms. All international travelers are recorded using another app named Yatri Web app and the data is thereafter accessed by the Quarantine Watch app to track their movements. Similarly passengers arriving into the State via rail and air are also tracked and the data accessed by the Quarantine app to track and monitor their movement. The State has also introduced a web application, named Critical Patient Tracking System for the health department to track critical patients across the State.

Similar apps to verify maintenance of quarantine norms using geotagged selfies and other surveillance technology have been introduced by other ULBs in the country too, viz. Hyderabad, Mumbai, Ahmedabad, Gandhinagar and Rajkot. In Ahmedabad for instance, automatic number plate recognition (ANPR) cameras located at key intersections capture and map the registration number of vehicles passing the intersections. The goal is to track individuals who break containment and quarantine norms and penalize them. In Gandhinagar too a COVID-19 tracking application has been implemented to track real-time movement of quarantined individuals. An alert message is sent to the command and control center if individuals move outside the quarantined zone. In Rajkot too surveillance is carried out through CCTV cameras for crowd management, enforcement of lockdowns and tracking and monitoring purposes. In each of these cases the ULB webpage has become an important resource to disseminate COVID related information to the public and also to administer the surveillance strategies.

In other instance of technology use in the South Indian State of Kerala robots have been deployed in public places to dispense hand-sanitizers (Sahasranamam, 2020). Robots have also been deployed in hospitals to carry food and medicines to patients in isolation wards. The State has also introduced an application named GoK-Kerala-Direct to send COVID-19 related updates and travel information via phone calls and text messages to individuals who do not own a smartphone. In Kerala civic authorities have also utilized telephone and mobile phone call records, surveillance footage from CCTV cameras and location data from mobile phones to track movement of infected people and map their contacts.

In early April the Indian Government launched the Aarogya Setu app. All government and private sector employees as well as individuals residing within containment zones are mandated to download the app on their smartphones. Some food delivery companies have also mandated their employees to download this app (Clarance, 2020). The app developed by India's National Informatics Center utilizes a smartphone's GPS system and Bluetooth to collect location data. The app compares the location data with the national database of known cases of COVID infection to inform users if they have come in contact with anyone with COVID-19. The data is also shared with the government. The app is available in 11 Indian languages. If a user tests positive for COVID the app will share his/ her location with the government. The Aarogya Setu app is the Modi government's approach taken to curb the spread of COVID-19 by using ICTs and artificial intelligence.

\section{CONCLUSION}

The COVID-19 pandemic has caused a social, economic and public health crisis. Global total confirmed cases of COVID is roughly 12.3 million and the total number of global deaths is 555,531 (Retrieved from the John Hopkins Coronavirus Resource Center on July 10, 2020). Total number of cases in India is 793,802 with 21,604 death (Retrieved from the John Hopkins Coronavirus Resource Center on July 10, 2020). Non-pharmaceutical interventions to curb the spread of the virus include measures such as social distancing, lockdowns and quarantine. The Indian Government has turned to the use of information and communication technologies which is an integral part of the Government's strategy to curb the spread of the virus. The current Indian government led by Prime Minister Mr. Narendra Modi has emphasized the informationization of government practices to instill a culture of modernization, efficiency and professionalism among government agencies since coming to power in 2014. 
The ideology has gained most traction among ULBs for urban governance purposes. Almost following an ideology that Alvarez and Rosen describe as "frame urban problems into technological problems, to be addressed by technological solutions" (Alvarez Leon and Rosen, 2019). In the face of the COVID-19 pandemic this ideology of technological solution has been most prevalent and State and local government bodies have utilized geospatial technologies and a variety of other surveillance technologies as part of a strategy to monitor, track and enforce quarantine norms. However, several important questions remain unanswered. What about individual privacy rights? Are appropriate laws being followed? Who will address questions on civil liberties? Has there been a concerted effort to introduce any safeguards to the rampant use of technology? Is technology use a suitable and the ultimate solution to the pandemic? What about the feasibility of using such technologies? Do these practices reinforce authoritarian governmentalities where it is acceptable for government agencies to govern at a distance using surveillance technologies enabling a "God's eye view" (Bondi \& Domosh, 1992) of its citizens and their movement?

A natural progression to this article will delve into such questions to seek answers to some of these very important and pertinent questions. 


\section{REFERENCES}

Alvarez, L., \& Rosen, J. (2020). Technology as ideology in urban governance. Annals of the Association of American Geographers, 110(2), 497-506. doi:10.1080/24694452.2019.1660139

Bondi, L., \& Domosh, M. (1992). Other figures in other places: On feminism, postmodernism and geography. Environment and Planning. D, Society \& Space, 10(2), 199-213. doi:10.1068/d100199

Boulos Kamel, M., \& Geraghty, E. (2020). Geographical tracking and mapping of coronavirus disease COVID-19/ severe acute respiratory syndrome coronavirus 2 (SARS -CoV-2) epidemic and associated events around the world: How 21st century GIS technologies are supporting the global fight against outbreaks and epidemics. International Journal of Health Geographics, 19(8), 8. Advance online publication. doi:10.1186/s12942-02000202-8 PMID:32160889

Center for Disease Control and Prevention. (n.d.). Get the Facts about Coronavirus. Available online at the CDC website at https://www.cdc.gov/coronavirus/2019-ncov/symptoms-testing/symptoms.html

Clarance, A. (2020). Aarogya Setu: Why india's Covid-19 contact tracing app is controversial. Available online on BBC News at https://www.bbc.com/news/world-asia-india-52659520

Datta, A. (2020). Self(ie)-governance: Technologies of intimate surveillance in India under COVID 19. Dialogues in Human Geography, 10(2), 234-237. doi:10.1177/2043820620929797

Du, J., King, R., \& Chanchani, R. (2020). Tackling Inequality in Cities is essential for fighting COVID-19. Available online at https://www.wri.org/blog/2020/04/coronavirus-inequality-cities

John Hopkins Coronavirus Resource Center. (n.d.). Available at https://coronavirus.jhu.edu/map.html

Mukherjee, F. (Forthcoming). Institutional networks of association for GIS use - The case of an urban local body in India. Annals of the Association of American Geographers. Advance online publication. doi:10.1080/ 24694452.2019.1691495

Roser \& Ortiz-Ospina. (2013). Global Extreme Poverty. Retrieved from: 'https://ourworldindata.org/extremepoverty'

Sahasranamam, S. (2020). India: how coronavirus sparked a wave of innovation. Available online on The Conversation at https://theconversation.com/india-how-coronavirus-sparked-a-wave-of-innovation-135715

Smart Cities Council. (2020). Pune, Surat, Bengaluru and Tumakuru use Command \& Control Centers as Covid-19 war rooms. Available online at https://india.smartcitiescouncil.com/article/pune-surat-bengalurutumakuru-use-command-control-centers-covid-19-war-rooms

WHO Director-General's statement on IHR Emergency Committee on Novel Coronavirus (2019-nCoV). (n.d.). Available online at https://www.who.int/news-room/detail/29-06-2020-covidtimeline

\section{ENDNOTE}

A containment zone is an area of 100 meters radius around the premises of a COVID-19 positive case which will be sealed for 28 days. 